\title{
Deliver Us From Evil: \\ The Effects of Mortality Salience and Reminders of 9/11 on Support for President George W. Bush
}

\author{
Mark J. Landau \\ University of Arizona \\ Sheldon Solomon \\ Skidmore College \\ Jeff Greenberg \\ University of Arizona \\ Florette Cohen \\ Rutgers University \\ Tom Pyszczynski \\ University of Colorado, Colorado Springs \\ Jamie Arndt \\ University of Missouri \\ Claude H. Miller \\ University of Oklahoma \\ Daniel M. Ogilvie \\ Rutgers University \\ Alison Cook \\ University of Missouri
}

According to terror management theory, heightened concerns about mortality should intensify the appeal of charismatic leaders. To assess this idea, we investigated how thoughts about death and the 9/11 terrorist attacks influence Americans' attitudes toward current U.S. President George W. Bush. Study 1 found that reminding people of their own mortality (mortality salience) increased support for Bush and his counterterrorism policies. Study 2 demonstrated that subliminal exposure to 9/ 11-related stimuli brought death-related thoughts closer to consciousness. Study 3 showed that reminders of both mortality and 9/11 increased support for Bush. In Study 4, mortality salience led participants to become more favorable toward Bush and voting for him in the upcoming election but less favorable toward Presidential candidate John Kerry and voting for him. Discussion focused on the role of terror management processes in allegiance to charismatic leaders and political decision making.
Keywords: terror management theory; terrorism; 9/11; George W. Bush; election politics; charismatic leaders

It is [fear] that makes people so willing to follow brash, strong-looking demagogues with tight jaws and loud voices: those who focus their measured words and their sharpened eyes in the intensity of hate, and so seem most capable of cleansing the world of the vague, the weak,

Authors' Note: We thank the reviewers for their helpful comments. Correspondence concerning this article should be addressed to Mark J. Landau, University of Arizona, Department of Psychology, P.O. Box 210068, Tucson, AZ 85721-0068; e-mail: mjlandau@email.arizona.edu.

PSPB, Vol. 30 No. 9, September 2004 1136-1150

DOI: $10.1177 / 0146167204267988$

(C) 2004 by the Society for Personality and Social Psychology, Inc. 
the uncertain, the evil. Ah, to give oneself over to their direction-what calm, what relief.

$$
\begin{array}{r}
\text {-Ernest Becker, } \\
\text { The Birth and Death of Meaning (1971, p. 161) }
\end{array}
$$

Starting with Sigmund Freud's (1921/1965) suggestion that leaders serve as substitute parent figures, psychologists of diverse theoretical persuasions have argued that the popularity of leaders depends, at least in part, on the extent to which they meet the pressing psychological needs of their followers (e.g., Becker, 1973; Bord, 1975; Ehrhart \& Klein, 2001; Fromm, 1941; Kirkpatrick \& Locke, 1996; Pillai, 1996; Redl, 1942). Terror management theory (TMT) (Greenberg, Pyszczynski, \& Solomon, 1986; Solomon, Greenberg, \& Pyszczynski, 1991) posits that one of the most basic functions that leaders serve is that of helping people manage a deeply rooted fear of death that is inherent in the human condition. Initial empirical support for this point was provided by Cohen, Solomon, Maxfield, Pyszczynski, and Greenberg's (in press) finding that reminders of mortality increase support for charismatic leaders in a hypothetical election scenario. This analysis implies that when reminders of one's vulnerability and mortality are highly salient, support for such leaders is likely to increase.

The terrorist attacks on the World Trade Center and Pentagon on September 11, 2001, seem highly likely to have dramatically increased the salience of such deathrelated concerns for most of the American people (Pyszczynski, Solomon, \& Greenberg, 2003). As one might predict from the terror management perspective, the popularity of the then and current American president, George W. Bush, increased dramatically in the days after the 9/11 terrorist attacks and has remained relatively high well into 2004. In the present article, we use the popularity of President Bush as a context for an "experimental case study" of the role of existential fear in promoting support for government leaders. Specifically, we examine (a) the effect of reminders of mortality on support for President Bush, (b) the link between 9/11-related stimuli and the accessibility of deathrelated thoughts (which have been shown to mediate the effect of mortality salience on the pursuit of faith in one's cultural worldview; for a review, see Pyszczynski, Greenberg, \& Solomon, 1999), and (c) the impact of reminders of $9 / 11$ on the popularity of President Bush.

\section{TERROR MANAGEMENT THEORY}

Building on the writings of Ernest Becker (1971, 1973, 1975), TMT begins with the assumption that humans share with all animals a fundamental orientation toward continued survival, along with many of the same biological and psychological systems designed for self-preservation. Humans are unique, however, in their capacity for self-consciousness, symbolic thought, and imagining possible future events. Despite their adaptive value, these cognitive abilities render humans aware that their own death is inevitable and possible at any moment, a recognition that conflicts with the biological propensity for continued existence and therefore gives rise to the potential for debilitating anxiety. To manage the potential for anxiety that this awareness produces, people deny that physical death implies absolute annihilation by maintaining faith in a personalized version of a cultural worldview: a set of humanly constructed, culturally derived, and socially validated beliefs about the nature of reality that provides meaning and the promise of literal or symbolic immortality to those who uphold culturally prescribed standards of value. Faith in cultural meaning and the perception of oneself as an object of value within that scheme provide a protective shield against the potential for anxiety that results from one's awareness of the inevitability of death.

The most prominent line of empirical support for TMT comes from tests of the mortality salience (MS) hypothesis, which states that if the cultural worldview functions to provide protection against death-related concerns, then reminders of death should intensify efforts to bolster and defend faith in the worldview. This broad hypothesis has been supported by a wide range of studies demonstrating the many ways in which MS increases defense of one's worldview (for reviews of empirical support for TMT, see Greenberg, Solomon, \& Pyszczynski, 1997; Solomon, Greenberg, \& Pyszczynski, in press). This body of research has operationalized MS in a variety of ways and has included control inductions that prime aversive topics other than death (e.g., physical pain, social rejection, uncertainty) and that consistently fail to produce effects parallel to MS on the primary measures of worldview defense. Research also has shown that effects parallel to MS are not produced by heightened self-awareness, the salience of cultural values, meaninglessness, or high cognitive load (e.g., Greenberg et al., 1995). In addition, internal analyses consistently reveal that terror management defenses are not mediated by the participant's current emotional state. This large body of evidence thus strongly suggests that MS effects result specifically from activating deathrelated cognitions.

TMT posits that terror management defenses are ultimately concerned with the implicit knowledge of death rather than with consciously experienced terror per se (see Greenberg et al., 2003). Based on a large body of evidence, Pyszczynski et al. (1999) proposed a dual process model of the cognitive processes through which 
thoughts of death affect behavior. This model posits that conscious contemplation of mortality first arouses direct threat-focused proximal defenses involving suppression of death-related thoughts or pushing the problem of death into the distant future by denying one's vulnerability to various risk factors (e.g., promising to get more exercise). Once death-related thought is no longer in consciousness, distal symbolic terror management defenses, which serve to bolster faith in the meaningful worldview and one's sense of self-worth, are activated to manage the potential for anxiety engendered by heightened accessibility of implicit death-related thought. Once these defenses have been employed, deaththought accessibility dissipates back to baseline level. In sum, whereas more straightforward proximal defenses against death serve to push death out of awareness, it is the sustained perception of oneself as a person of value in a world of meaning that allows people to avert the potential for anxiety that results from the increased accessibility of death-related thought (for recent reviews of research supporting this model, see Arndt, Cook, \& Routledge, in press; Solomon et al., in press).

\section{THE POPULARITY OF PRESIDENT GEORGE W. BUSH}

Prior to the September 11, 2001, terrorist attacks on the World Trade Center and Pentagon, President Bush's popularity among the American people was tenuous. He had lost the popular vote in the 2000 election and won the presidency after a narrow victory in the Electoral College that was ultimately decided by the Supreme Court after a highly controversial near-draw in the critical electoral state of Florida. A collection of national public opinion polls by PollingReport.com (2004; including Fox News, CNN/USA Today/Gallup Polls, and ABC News/Washington Post Polls) indicate that President Bush's approval ratings hovered around $50 \%$ in the weeks preceding the terrorist attacks. A front page article in The New York Times (Berke \& Sanger, 2001) on September 9, 2001, reported intense efforts by the White House staff to increase the president's popularity in the face of a sagging economy and critical evaluations of his style and strategy by leading Republican legislators. All of this changed virtually overnight, with polls indicating an unprecedented $88 \%$ to $90 \%$ approval rating as early as September 13, 2001 (Morin \& Deane, 2001; PollingReport.com, 2004). Opinion polls also showed overwhelming support for Bush's handling of the terrorist crisis, the restriction of civil liberties, the military action against the Taliban in Afghanistan, and at least initially, the preemptive war on Iraq (Dworkin, 2002; Etzioni, 2002; Huddy, Khatid, \& Capelos, 2002; Langer, 2001; Moore, 2001; Toner \& Elder, 2001).

This is not to say that Bush's actions and policies have not been subjected to intense scrutiny, criticism, and skepticism in some quarters (e.g., Alterman \& Green, 2004; Anonymous, 2004; Clarke, 2004; Dean, 2004; Frank, 2004; Humberman, 2004; Phillips, 2004; Risen, 2004; Suskind, 2004; Unger, 2004; Waldman, 2004; Woodward, 2004), but Bush's popularity seemed to withstand such attacks well into early 2004, the final year of his current term as President, despite a variety of potentially damaging allegations that had come to light since his decision to proceed with a preemptive war on Iraq, including the reliance on faulty intelligence information regarding links of Iraq to al Qaeda and the 9/11 bombings, the presence of weapons of mass destruction, claims that initial discussion of plans for war on Iraq appeared to have been held soon after $9 / 11$, and protracted fighting that lasted long after the war was declared won. ${ }^{1}$

\section{TMT AND SUPPORT FOR PRESIDENT BUSH}

How might we understand the psychological forces bearing on the confidence and trust people are willing to place in their national leaders, especially in times of crisis? TMT posits that popular support for leaders is partly the result of the need to allay a deeply rooted fear of death. According to TMT, people are motivated to conceive of themselves as valued participants in a cosmically significant cultural scheme rather than physical creatures subject to decay and death. Investing faith in the leader of that scheme to assure symbolic prosperity facilitates the maintenance of this buffer. The appeal of the leader lies in his or her perceived ability to both literally and symbolically deliver the people from illness, calamity, chaos, and death as well as to demonstrate the supremacy of the worldview. Building on the ideas of Freud, Ferenzci, Rank, Redl, and Fromm, Becker (1971, $1973,1975)$ proposed that over the course of socialization, the primary sources of psychological security, those entities that sustain the sense of life as meaningful and one's self as significant, shift from one's parents to the culture and its figures of power, authority, and righteousness. As a result of this transference process, Becker (1975) viewed secular leaders as representing not only rational, objective policy makers but, similar to their religious counterparts, assuming the role of "death-dealer and death-defier" (p. 42) - the embodiments of invulnerability and symbolic supremacy (see also Lifton, 1968).

From this perspective, President Bush's appeal may lie in his image as a protective shield against death, armed with high-tech weaponry, patriotic rhetoric, and the resolute invocation of doing God's will to "rid the world of evil" (Purdum, 2001, p. 2; see also Carney \& Dickerson, 2001). Indeed, Woodward (2004) describes how when asked if he seeks his father's advice on Iraq, the president replied, "You know, he is the wrong father 
to appeal to in terms of strength. There is a higher father that I appeal to" (p. 421). President Bush may provide a sense of protection from the overwhelming terrorist threat, both literally by ensuring physical safety and symbolically by acting on America's behalf in a heroic triumph over evil (symbolized by Bush landing aboard an aircraft carrier in a Navy jet to declare the war in Iraq to be functionally over and by the dramatic toppling of Saddam Hussein's statue in Baghdad). In sum, TMT suggests that people avoid a potentially debilitating preoccupation with personal frailty and finitude, in part, by transferring power to and investing faith in a powerful authority. Such a central locus of control over life and death appears to assure indefinite perpetuation by assuming mastery over nature and tragedy and upholding the cultural meaning system that imbues individual lives with transcendent meaning, order, and permanence.

If loyalty to leaders stems in part from terror management concerns, then reminders of mortality should increase Americans' support for President Bush. A number of previous findings are generally consistent with this hypothesis. A substantial body of research indicates that MS engenders inflated regard for a wide array of people, concepts, and objects that represent the culture to which the participants subscribe (reviewed by Greenberg et al., 1997; Solomon et al., in press). For example, Greenberg et al. (1990) found that, compared to those primed with another aversive outcome, death-primed individuals expressed especially favorable evaluations of essays and their authors who praised the United States and especially negative evaluations of anti-U.S. essays and their authors. MS also has been shown to incite aggressive behavior against those who impinge on one's worldview: McGregor et al. (1998) found that death-primed participants administered excessive amounts of an aversively spicy hot sauce to a target who verbally attacked their political orientation. Research by Greenberg, Simon, Porteus, Pyszczynski, and Solomon (1995) showed that following MS, American participants became more reluctant and uncomfortable when treating an American flag inappropriately. Finally, Arndt, Greenberg, and Cook (2002) found that subliminal death primes (and explicit MS treatments after a delay) can increase the accessibility of nationalistic cognitions. Taken together, these findings provide convergent support for the role of intimations of mortality in people's allegiance to and defense of the nationalistic aspects of their cultural worldviews.

Of most direct relevance for present purposes, Cohen et al. (in press) recently demonstrated that MS enhanced the appeal of a charismatic leader who promotes a grand vision and promises citizens a significant role in a noble mission in a hypothetical election sce- nario. More specifically, MS increased preference for a hypothetical political candidate portrayed as having charismatic qualities but not for ones portrayed as task oriented or relationship oriented. The studies reported here seek to extend these findings by providing an "experimental case study" of the role of death-related concerns in general, and 9/11-related concerns in particular, in promoting support for President George W. Bush.

\section{STUDY 1}

Study 1 was designed to test the hypothesis that to the extent that support for President Bush derives in part from terror management needs, then MS should increase support for Bush and his policies. To test this hypothesis, we primed American participants with thoughts of either death or a control topic and then measured their support for President Bush and his antiterrorism policies.

\section{Method}

\section{PARTICIPANTS}

Ninety-seven undergraduates at Rutgers University (65 women, 32 men) volunteered to participate in return for extra credit in their psychology class in October 2003 .

\section{MATERIALS AND PROCEDURE}

The study was run in a single session in a psychology class. The experiment was described as a short study of the relationship between personality attributes and opinions about social issues. Each participant was given a questionnaire packet and was asked to complete each question in the booklet in the order in which it appeared. The MS manipulation followed two filler questionnaires included to sustain the cover story and obscure the true purpose of the study. In the MS condition, participants responded to two open-ended questions (used in previous TMT studies, e.g., Greenberg et al., 1990; Rosenblatt, Greenberg, Solomon, Pyszczynski, \& Lyon, 1989): "Please briefly describe the emotions that the thought of your own death arouses in you" and "Jot down, as specifically as you can, what you think will happen to you as you physically die and once you are physically dead." Control participants responded to parallel questions about watching television. All participants then completed a self-report mood scale (PANAS-X; Watson \& Clark, 1991) to assess possible affective consequences of the MS induction and read a short literary passage to serve as a delay because previous research (Greenberg, Pyszczynski, Solomon, Simon, \& Breus, 1994) has shown that MS increases worldview defense most consistently when there is a delay between the MS induction and dependent variable assessment. 
Participants then read the following essay expressing a highly favorable opinion of the measures taken by President Bush with regard to 9/11 and the Iraqi conflict:

It is essential that our citizens band together and support the President of the United States in his efforts to secure our great Nation against the dangers of terrorism. Personally, I endorse the actions of President Bush and the members of his administration who have taken bold action in Iraq. I appreciate our President's wisdom regarding the need to remove Saddam Hussein from power and his Homeland Security Policy is a source of great comfort to me. It annoys me when I hear other people complain that President Bush is using his war against terrorism as a cover for instituting policies that, in the long run, will be detrimental to this country. We need to stand behind our President and not be distracted by citizens who are less than patriotic. Ever since the attack on our country on September 11, 2001, Mr. Bush has been a source of strength and inspiration to us all. God bless him and God bless America.

They were then asked to respond to three questions: "To what extent do you endorse this statement?" "I share many of the attitudes expressed in the above statement," and "Personally, I feel secure knowing that the President is doing everything possible to guard against any further attacks against the United States." All responses were made on 5-point scales $(1=$ strongly agree, 5 = strongly disagree). These responses were then reversed-scored so that higher numbers were indicative of greater support for the president.

\section{Results and Discussion}

Support for the president. The responses on the three questions demonstrated good internal reliability $(\alpha=$ $.94)$ so they were combined to yield a composite agreement score, which was submitted to a 2 (MS vs. control) $\times$ 2 (gender) ANOVA. There was no main effect or interaction for gender, $p s>$.2. However, the predicted main effect for MS was obtained, $F(1,93)=112.48, p<.001$; those in the MS condition reported higher support for President Bush $(M=4.16, S E=.145)$ than those in the control prime condition $(M=2.09, S E=.131)$. Analyses conducted on the individual items making up our composite measure revealed significant effects on all three items, all $p \mathrm{~s}<.01$, with MS increasing approval of Bush and his policies on each item. It is noteworthy that the mean in the control group is on the disagreement side of the scale's midpoint, whereas the mean in the MS condition is on the agreement side. Also, the effect size is large, $\eta^{2}=.55$.

Affect. To assess whether MS affected mood, we performed a MANOVA and ANOVAs on the subscales of the
PANAS-X (Watson \& Clark, 1991) and ANOVAs on the aggregate positive and negative affect scales as well. ${ }^{2}$ Consistent with previous TMT research demonstrating that MS does not engender affect, there were no significant differences found for these analyses. To ensure that the MS effect reported above was not mediated by affect, we conducted an analysis of covariance (ANCOVA) with the affect subscale scores (including positive and negative affect) as covariates and the effect of MS remained statistically intact. Thus, we are quite confident that, as in past research, this finding is not caused by affective differences between MS and TV salience conditions.

\section{9/11 and Support for Bush}

In his 2004 reelection effort, President Bush sought to establish his effectiveness in combating terrorism and his ability to protect people from the alleged threats associated with terrorism. Political advertisements in support of the Bush campaign have featured images of 9/11 and its aftermath and emphasized the President's ability to preserve national security (Rutenberg \& Sander, 2004). Because the prosecution of the war on terror has become a touchstone of Bush's reelection campaign, one might wonder whether references to 9/ 11 are effective in increasing support for President Bush and, if so, why.

Understanding these reactions requires a theoretical framework from which to assess the psychological significance of terrorism-related events. In this vein, Pyszczynski et al. (2003) recently portrayed the events of 9/11 as a "natural" MS induction and discussed how many of the symbolic defenses prompted by $9 / 11$ (e.g., veneration for culturally sacred objects, such as flags) paralleled those found in response to MS inductions used in terror management research. Based on these affinities, Pyszczynski et al. proposed that symbolic responses to $9 / 11$ are the product of a potent doublebarreled threat posed by the events: vivid and unceasing depictions of death and destruction compounded by a massive threat to America's sense of military and financial power and moral righteousness. In concert, these threats should encourage bolstering of Americans' faith in the symbolic structures that constitute the dominant cultural worldview. From this perspective, many symbolic defenses in response to $9 / 11$ represent efforts to reaffirm the integrity and absolute validity of the American worldview in response to increased accessibility of implicit death-related thoughts (see also Miller \& Landau, in press). However, we know of no direct experimental evidence that terrorism-related events parallel the effect of MS primes in increasing death-thought accessibility or that 9/11-related thoughts play a role in increased attraction to a leader. In Study 2, we therefore 
sought to discover whether 9/11-related thought functions in the same way as death-related thought in producing heightened implicit death accessibility. Then, in Study 3, we determined if reminders of 9/11 function like MS primes in increasing support for President Bush.

\section{STUDY 2}

Support for the dual process model has been obtained from studies showing that MS inductions that completely by-pass the conscious consideration of death can influence symbolic defenses (Arndt, Greenberg, Pyszczynski, \& Solomon, 1997). More specifically, Arndt et al. demonstrated that presenting death-related words beneath conscious awareness led to an immediate increase in death-thought accessibility relative to neutral or negative control words. Furthermore, subliminal death stimuli led to an immediate increase in worldview defense (increased preference for a pro-American essay and its author as opposed to an anti-American author), whereas previous research has shown that supraliminal death stimuli produce increased death accessibility and worldview defense only after a delay and distraction. In short, the increased accessibility of death-related thought outside of focal attention-the condition shown to engender symbolic defenses-occurs at an unconscious level.

Other research has found that threats to terror management defenses increase death-thought accessibility, whereas strengthening those defenses tends to reduce it (Arndt, Greenberg, Solomon, Pyszczynski, \& Simon, 1997). For example, increases in death-thought accessibility have been shown to follow explicit reminders of one's physical nature (Goldenberg, Cox, Pyszczynski, Greenberg, \& Solomon, 2002), salient threats to a close relationship (Mikulincer, Florian, \& Hirschberger, 2003), and confrontations with events that violate the belief in a just world (Landau et al., in press). Based on these lines of research, we predicted that to the extent that $9 / 11$ functions like an MS prime in activating unconscious concerns about mortality, subliminal exposure to 9/11-related stimuli should result in an increase in the accessibility of death-related thoughts. This would establish the cognitive link between $9 / 11$ and deaththought accessibility assumed by our analysis of the effects of $9 / 11$.

\section{Method}

\section{PARTICIPANTS AND DESIGN}

Participants were 52 introductory psychology students at the University of Missouri-Columbia who were randomly assigned to receive one of three subliminal primes: 911, WTC, or 573. This study was conducted approximately 1 month after the $9 / 11$ attacks. The dependent variable was the accessibility of death-related words. Six participants were excluded ( 4 who did not complete the questionnaires correctly; 2 due to errors with their materials). Therefore, a total of 46 participants (26 women, 20 men) were included in the analyses.

\section{PROCEDURE}

Upon participants' arrival, the experimenter introduced himself and described the experiment as exploring the ability to perceive word relationships and personality traits. Participants were told that they would complete some personality questionnaires, a computer task, and then some additional word perception measures. Participants were assured of their anonymity and then read and signed a consent form before the procedures commenced.

After the participants completed some filler personality questionnaires (which served to maintain the cover story), they were escorted into smaller cubicles that contained the computers. The experimenter then gave the instructions for the word-relation task, which required participants to decide as quickly as possible whether two words that flashed sequentially on the computer were related or unrelated by pressing the right shift key or the left shift key, respectively. For example, if the words flower and rose were presented, they should press the right shift key to indicate that they are related, but if the words sneaker and fajita were presented, they should press the left shifted key to indicate that they are not. The experimenter then turned off the room light to reduce the glare on the screen. The appropriate keys and the light switch were illuminated via glow-in-the-dark stickers.

When participants were finished with the computer task, they were told to turn on the light and complete the packet of word perception measures lying on a clipboard next to the computer. The questionnaires included a death-theme-accessibility measure followed by some additional word puzzles and then some manipulation check questions to assess participants' awareness of the stimuli display. Participants were told to put the completed questionnaire in a blank envelope provided and then put the envelope in the box located under the desk. When participants were finished with both of these tasks, they were instructed to crack the door of the cubicle. Then, participants were probed for suspicion, fully debriefed, and thanked for their time.

\section{MATERIALS}

Apparatus and program for stimulus presentation. Stimuli were presented on a 15-in. Gateway color monitor controlled by an IBM-compatible computer. The task was 
presented using DMASTR display software developed at Monash University and at the University of Arizona by K. I. Forster and J. C. Forster. The program synchronizes the timing of the display and uses normal, bit-mapped fonts. The first few frames presented instructions and three practice stimuli centered on the screen. There were then 10 trials sequentially presenting three words centered on the screen. The first and third words were the target words for which participants were supposed to determine the presence or absence of a relationship. Actually, these two words served as a forward mask (and fixation point) and backward mask, respectively, and were displayed for $356 \mathrm{~ms}$. The critical subliminal prime, either 911, WTC, or 573 depending on the condition, was presented between the two masked words for 28.5 ms. Both 911 (referring to the date) and WTC (World Trade Center) were chosen as the terrorism primes due to their widespread association with the terrorist attacks on the World Trade Center on September 11, 2001. Because 911 is also associated with emergencies, we also included WTC as a prime, which presumably had little meaning until its increased media usage following the terrorist attacks. The control prime, 573, was chosen because of its familiarity (as the area code for Columbia, Missouri) and its number of characters matched that of the other two primes. Which version of the program was presented was set by another research assistant to keep the experimenter blind to conditions.

Accessibility. A word fragment completion task, similar to tasks used by other researchers (e.g., Gilbert \& Hixon, 1991; Greenberg et al., 1994), was introduced as a measure "being pre-tested for future studies" but was actually used to assess the accessibility of death-related themes. The measure consisted of 34 word fragments that participants were instructed to complete with the first word that came to mind. Six of the 34 fragments could be completed with either a neutral or death-related word. For example, the fragment $\mathrm{COFF}_{-}$_ could be completed as COFFEE (a neutral word) or COFFIN (a death-related word). The possible death-related words were buried, skull, murder, stiff, coffin, and grave.

\section{Results and Discussion}

Checks on awareness of subliminal stimuli. To assess participants' awareness of the subliminal stimuli, we examined their responses to the five questions presented at the conclusion of the session. In response to the first question-How many words did you see in each display (each trial for which you were to make relational judgments)?-Forty of the 46 participants indicated that they saw two words in each trial display. With the next question-Did you ever see more than two words flash at a time-only 1 participant indicated that he may have seen more than two words. Pearson chi-square tests indicated that there were no differences between prime conditions, $\chi^{2}(2, N=46)<2.10, p>.34$. For the questions that asked if the word was the same or different and asked participants to list all possibilities, all of the participants left them blank. A Pearson chi-square test conducted on the multiple-choice question-Assuming that there was something flashed between the two target words, which of the following do you think it may have been?-revealed no differences between conditions, $\chi^{2}(10, N=46)=11.42, p>.32$. Thus, as in previous research using this manipulation (e.g., Arndt et al., 1997a, 2002), there was no conscious retrospective awareness of the prime.

Accessibility of death-related thoughts. A one-way ANOVA was conducted on the accessibility of death thoughts, as indicated by the number of death-related word fragments, and showed a marginal difference between prime groups, $F(2,43)=3.03, p<.06, \eta^{2}=.12$. Of course, our prediction corresponded to a 2 versus 1 contrast rather than a linear trend (e.g., Rosenthal, Rosnow, \& Rubin, 2000). Thus, we conducted two orthogonal contrasts. The first answers the following question: Does being subliminally primed with symbols related to the recent terrorist attacks increase death-thought accessibility compared to a control condition? This planned contrast confirmed our hypothesis, revealing that participants in the terrorism prime conditions showed greater death-thought accessibility $(911=2.07, S D=.80$; WTC $=$ $1.80, S D=1.15)$ than those in the control condition $(573=$ $1.25, S D=.86), t(43)=2.34, p<.03$. The second contrast found that although the mean was a bit higher in the 911 condition than in the WTC condition, this difference was not statistically significant, $p>.44$.

Study 2 demonstrated that stimuli commonly associated with the 9/11 attacks (911 and WTC) produce an increase in death-thought accessibility, much like previous research has shown subliminal death-related stimuli do (Arndt et al., 1997a). This establishes the cognitive linkage between the 9/11 terrorist attacks and deaththought accessibility that is central to Pyszczynski et al.'s (2003) analysis of how Americans reacted to these attacks and that we posit to underlie the effect of reminders of the 9/11 attacks on Americans' approval of President Bush and his policies.

\section{STUDY 3}

Having established that cognitions related to $9 / 11$ function much like MS primes in increasing deaththought accessibility, we next examined whether reminders of $9 / 11$ were functionally equivalent to MS primes in increasing support for President Bush. To test this hypothesis, we primed participants with thoughts of 
death, 9/11, or an aversive control topic and then measured their attitudes toward Bush.

Because a nonaversive control prime (television salience) was used in Study 1, the possibility remains that the findings of that study were the result of thinking about negative events in general and not necessarily death, per se. To address this alternative, Study 3 used a control prime likely to be aversive to students: thoughts of an upcoming exam. Indeed, Greenberg et al. (1995) found that this prime produced more negative affect than MS. We also wanted to assess possible effects of reminders of mortality and $9 / 11$ on general political orientation. From our perspective, the increase in favorability toward Bush reflects the effects of death reminders on the appeal of a leader who promotes security and the vanquishing of evil, but an alternative possibility is that reminders of death or $9 / 11$ simply make people more politically conservative, which in turn makes Bush more appealing. Thus, we included a simple measure assessing participants' self-reported position along a continuum from very conservative to very liberal.

\section{Method}

\section{PARTICIPANTS}

Participants were 74 (46 women, 28 men) Rutgers undergraduates who volunteered to be in the study for extra credit in February 2004.

\section{MATERIALS AND PROCEDURE}

The experiment was run in a classroom setting. The procedure was virtually identical to Study 1: Participants were told that we were interested in the relationship between personality attributes and opinions on social issues. After completing filler questionnaires to sustain the cover story, participants were randomly assigned to an MS, exam salience, or terrorism prime condition. MS participants completed the typical two open-ended questions about death; exam salience participants completed parallel questions about an upcoming exam; terrorism salience participants were asked to "Please describe the emotions that the thought of the terrorist attacks on September 11, 2001, arouses in you" and "Write down as specifically as you can what happened during the terrorist attacks on September 11, 2001." After completing the PANAS-X to assess the affective consequences of the MS and terrorism salience inductions and reading the delay paragraph, participants were asked to read the same paragraph praising George Bush used in Study 1 and to answer the same three questions about it. These items demonstrated good internal reliability $(\alpha=.89)$, so we formed a composite index indicative of support for the president. Finally, after completing some filler demographic questions, participants were asked to indicate

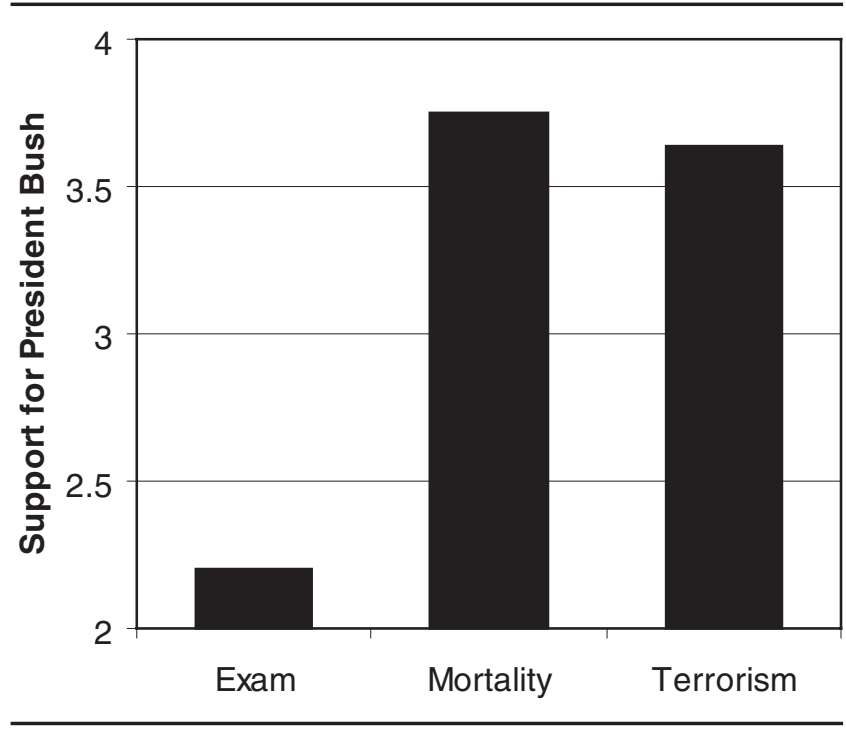

Figure 1 Study 3: Support for George W. Bush as a function of priming condition.

their political orientation on a scale from 1 (very conservative) to 9 (very liberal).

\section{Results and Discussion}

Support for the president. There was no effect of, or interaction with, gender, $F \mathrm{~s}<1$. A one-way ANOVA (priming condition) on the liking for Bush composite revealed a significant effect, $F(2,71)=43.12, p<.001$ (see relevant means in Figure 1). A 2 versus 1 contrast confirmed our hypothesis, revealing that participants in MS and 9/11 salience conditions showed greater support for Bush and his policies compared to those in the control condition, $t(72)=9.31, p<.001$. A second contrast found that although the mean was a bit higher in the MS condition, this difference was not statistically significant, $p>.8$. As in Study 1, exam salient control participants were on the disagreement side of the scale, whereas MS and 9/11salient participants were on the agreement side of the scale; there was also a large effect size, $\eta^{2}=.55$. These results thus replicate those of Study 1 and show that reminders of 9/11 have the same effect as MS in increasing the appeal of President Bush. As in Study 1, analyses of the individual items revealed significant effects on all three items, all $p$ s $<.01$, with identical patterns of statistically significant differences among means.

Affect. To assess whether MS affected mood, we performed a MANOVA and ANOVAs on the subscales of the PANAS-X (Watson \& Clark, 1991) and ANOVAs on positive affect and negative affect. Consistent with previous TMT research demonstrating that MS does not engender affect, there were no significant differences found for these analyses. 
Political orientation. A one-way ANOVA revealed no effect of the MS or 9/11 prime on political orientation, $F<1$, suggesting that these inductions enhanced affection for President Bush without altering political orientation per se. Overall, the sample was slightly liberal, with a mean of 5.8. To assess whether the priming effects were not exclusive to participants with a conservative political orientation, we conducted a regression in which the Bush approval composite was the dependent variable and prime condition, political orientation, and their interaction served as predictors. We observed the expected main effects for condition and political orientation, indicating higher approval in the MS and 9/11 conditions and the more conservative the participants were.

We also found an unanticipated significant interaction, $\beta=.74, S E=.07, t=1.96, p=.05$. We plotted the interaction in Figure 2 using 1 standard deviation above (liberal) and below (conservative) the mean of political orientation (Aiken \& West, 1991). The simple slopes for political orientation within each level of the priming condition are as follows: exam salience control, $\beta=-.48, t=$ $-4.11, p<.001$; mortality salience, $\beta=-.28, t=-1.53, p=$ .13 ; and $9 / 11$ salience, $\beta=-.06, t=-.32, p=.75$. To test whether these slopes were statistically different in pairwise fashion, we conducted three separate regressions to examine how political orientation interacts with exam versus mortality, exam versus $9 / 11$, and mortality versus $9 / 11$. The only significant interaction to emerge was the Political Orientation $\times$ Exam vs. $9 / 11$ Salience, $t=2.53, p$ $<.02$ (for MS vs. $9 / 11, t=1.28, p>.2$; exam vs. MS, $t=$ $1.01, p>.29)$. These results in conjunction with Figure 2 suggest that MS increased approval of Bush similarly for liberals and conservatives but that the terrorism prime had a stronger effect on liberals, such that in that condition, political orientation was a negligible predictor, and significantly less predictive of approval of Bush than it was in the exam control condition.

These results support the hypotheses that MS and a reminder of $9 / 11$ would both increase the appeal of President Bush regardless of political orientation. The interaction suggests that $9 / 11$ does so a bit less for the more conservative participants. We cannot offer a definitive interpretation for this unexpected pattern, but if it is not spurious, it may reflect the nature of the sample. The conservative group actually included 27 participants who circled 5, the midpoint of the scale. It may be that for politically middle-of-the-road people, certain aspects of Bush's handling of 9/11 were not appealing. More research with a broader sampling of political orientations is needed to explore this further, but it is important to keep in mind that both MS and 9/11 significantly increased the appeal of President Bush for our conservative and liberal participants.

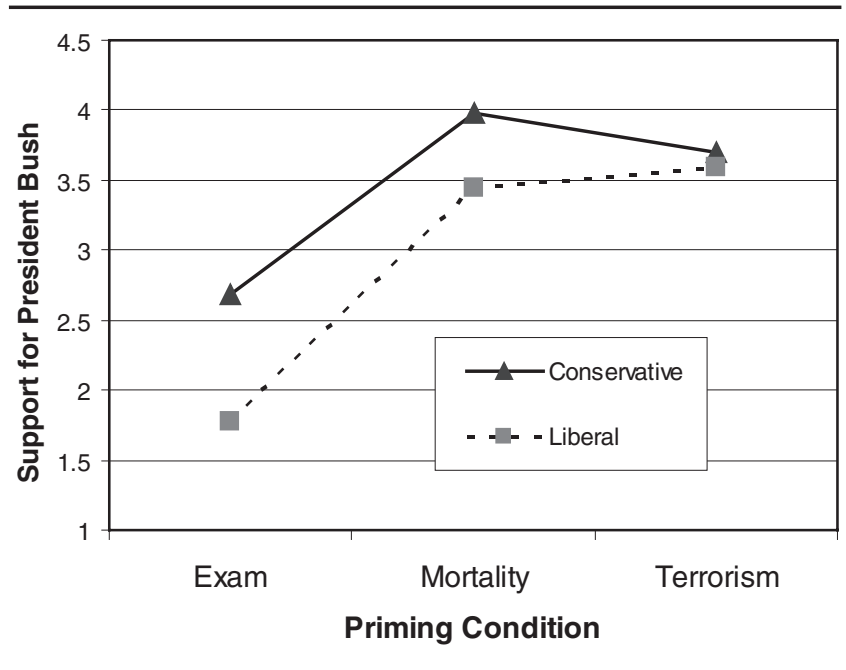

Figure 2 Study 3: Support for George W. Bush as a function of priming condition and political orientation.

STUDY 4

We have proposed that through his charismatic leadership style, President Bush represents a protective authority capable of assuaging existential concerns. Although the results of Studies 1 and 3 are consistent with this hypothesis, it is possible that the observed results are due to increased affection for anyone in a leadership position or with potential for U.S. leadership rather than Bush himself. Although Bush's current position as president and his other attributes make it impossible to find a leader for comparison who only differs on one dimension, because of the upcoming election as of May 2004 when we conducted this last study, we felt that Democratic presidential nominee Senator John Kerry would be the best comparison leader. Thus, participants in the following study were asked to rate either President Bush or the current Democratic presidential nominee John Kerry.

Also, because in Studies 1 and 3 we operationalized support for Bush as agreement with a paragraph praising Bush and his policies, it is possible that MS influenced reactions to particular statements in the paragraph (e.g., those that affirmed cultural or moral values), which then led to the increased favorability toward Bush. This operationalization also prevents us from ruling out the possibility that MS increased agreeability to any elaborate, persuasive message rather than a pro-Bush message per se. ${ }^{3}$ We address these alternatives in Study 4 by eliminating the essay and using straightforward questions designed to more directly assess support for Bush. Moreover, we included a question that allows us to directly compare the effect of MS on the likelihood of voting for either President Bush or presidential candidate Kerry in the upcoming presidential election. To further assess the 
specificity to concerns about mortality, in this study, we used a different aversive control topic, intense pain.

\section{Method}

\section{PARTICIPANTS AND DESIGN}

One hundred and fifty-seven students at Brooklyn College (95 women, 62 men) were randomly assigned to conditions in a 2 (mortality salient vs. intense pain salient control) $\times 2$ (evaluate George W. Bush vs. evaluate John Kerry) design. Participants completed the experimental materials individually on May 13, 2004.

\section{MATERIALS AND PROCEDURE}

The experimenter approached individuals in the college cafeteria and asked them to participate in a short study of personality attributes and social judgments. After giving verbal consent, each participant was given a questionnaire packet and asked to complete each question in the booklet in the order in which it appeared. The packet began with two filler questionnaires to sustain the cover story and obscure the true purpose of the study, followed by the manipulation of MS. In the MS condition, participants responded to the two openended questions used in Studies 1 and 3; in the intense pain condition, participants responded to two parallel questions: "Please describe the emotions that the thought of being in intense pain arouses in you" and "Write down as specifically as you can what you think will happen to you physically as you are in intense pain." All participants then completed a self-report mood scale (PANAS-X; Watson \& Clark, 1991) to assess possible affective consequences of the MS induction and read a short literary passage to serve as a delay.

The next page of the questionnaire booklet was titled "Opinion Survey." In the evaluate George W. Bush condition, participants were instructed to "Think for a moment about President George W. Bush and then answer the following questions by circling the number that best approximates your feelings." Four questions followed: "How favorably do you view George W. Bush?" "To what extent do you admire George W. Bush?" "To what extent do you have confidence in George W. Bush as a leader?" and "If you vote in the upcoming presidential election, how likely is it you will vote for George W. Bush?" In the evaluate John Kerry condition, participants read identical instructions and responded to identical questions about presidential candidate (rather than President) John Kerry. The questions were followed by 9point scales with endpoints marked not at all favorably and extremely favorably for the first question and not at all and very much for the remaining three questions. Finally, after completing some filler demographic questions, participants were asked to indicate their political orien-

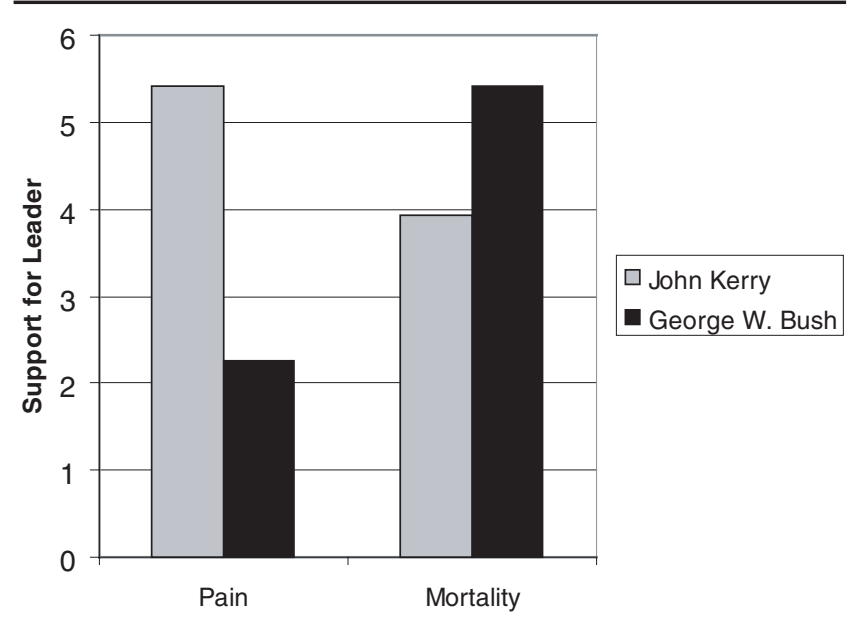

Figure 3 Study 4: Support for President George W. Bush and presidential candidate John Kerry as a function of priming condition.

tation on a scale from 1 (very conservative) to 9 (very liberal).

Results

Opinion survey. The four questions on the opinion survey demonstrated good internal reliability $(\alpha=.94)$ so we formed a composite index indicative of support for either Bush or Kerry. We then subjected the composite index scores to a 2 (MS vs. intense pain) $\times 2$ (evaluate Bush vs. evaluate Kerry) $\times 2$ (gender) ANOVA, which revealed main effects for mortality salience versus intense pain, $F_{(1,149)}=8.52, p=.004, \eta^{2}=.054$, and evaluating Bush versus Kerry, $F_{(1,149)}=8.48, p=.004, \eta^{2}=.054$, qualified by an interaction between these factors, $F_{(1,149)}=$ $64.00, p<.001, \eta^{2}=.30$ (see relevant means in Figure 3). The main effects were due to participants in the MS condition giving higher ratings $(M=4.68)$ to either candidate than those in the intense pain control condition $(M=3.83)$ and higher ratings of John Kerry $(M=4.67)$ than George Bush $(M=3.83)$. More important, however, an examination of the interaction revealed that although John Kerry was significantly more highly regarded than George Bush in the intense pain control condition, $t(75)=7.50, p<.001$, George Bush's evaluations increased in response to MS (across the midline of the scale), $t(76)=7.87, p<.001$, whereas John Kerry's evaluations declined, $t(77)=3.34, p=.001$, such that Bush was evaluated significantly more positively than Kerry when mortality was salient, $t(78)=3.69, p<.001$. Analyses conducted on the individual items making up our composite measure revealed significant effects on all items, including the voting decision item, all $p s<.001$, with identical patterns of statistically significant differences among means. 
Affect. To assess whether MS affected mood, we performed a MANOVA and ANOVAs on the subscales of the PANAS-X (Watson \& Clark, 1991) and ANOVAs on the aggregate positive and negative affect scales as well. These analyses revealed only two univariate main effects. Compared to the pain salience prime, MS led to less attentiveness $(p=.05)$, less positive $\operatorname{mood}(p<.03)$, and less sadness $(p<.05)$. To ensure that the MS effect reported above was not mediated by affect, we conducted separate analyses of covariance (ANCOVAs) with attentiveness, sadness, and positive affect entered separately as covariates. The results of the primary analyses remained statistically unaffected. Thus, we are quite confident that this finding is not caused by affective differences between MS and pain salience conditions.

Political orientation. Overall, the sample was moderately liberal, with a mean of 5.8. A 2 (MS vs. pain) $\times 2$ (Bush vs. Kerry) $\times 2$ (gender) ANOVA revealed no effects on political orientation, suggesting that the MS induction influenced evaluations of Bush and Kerry without altering political orientation per se. As in Study 3 , we assessed whether the priming effects were exclusive to participants with a conservative political orientation by regressing the approval composite on priming condition, leader condition, political orientation, and their interactions. We observed main effects for all variables, the predicted Prime $\times$ Leader interaction, and an unsurprising Political Orientation $\times$ Leader interaction $(p s<$ $.05)$, but no hint of a three-way interaction $(p>.46)$. These results indicate that MS intensified support for President Bush and reduced support for Kerry regardless of political orientation.

\section{Discussion}

The results of Study 4 demonstrate that compared to an intense pain prime, MS increased support for President Bush. In contrast, MS significantly reduced support for presidential candidate John Kerry. These results suggest that MS does not heighten affection for anyone associated with U.S. leadership, but Bush in particular. These results are consistent with Cohen et al.'s (in press) finding that MS heightens the appeal of a leader with a charismatic style and go further in demonstrating that MS can significantly reduce the appeal of some (potential) leaders. The Cohen et al. study found that MS reduced attraction to a hypothetical candidate with an egalitarian, relationship-oriented style; perhaps the reduced appeal of Kerry in this study reflects a perception of him as having such a style. Beyond comparing Bush to Kerry, the use of straightforward approval questions rather than agreement with an elaborate message provides direct evidence of the effect of MS on favorability of President Bush. Of importance, these results go beyond mere approval and reveal that in a complete reversal from the control condition, mortality-salient participants actually favored Bush in the upcoming presidential election.

\section{GENERAL DISCUSSION}

Study 1 explored the role of mortality concerns in American popular support for President Bush and found that MS increased agreement with a favorable assessment of Bush and his policies. Because issues of national security are a substantial component of the Bush administration's campaign strategy, we then explored the psychological impact of reminders of $9 / 11$. In Study 2, we found that paralleling the effects of subliminal death primes reported in previous research, subliminal presentations of 9/11-related stimuli (9/11 and WTC) increased death-thought accessibility. Study 3 extended these findings by demonstrating that making 9/11 salient was functionally equivalent to MS in increasing support for President Bush. Study 4 provided more direct evidence that MS intensifies support for President Bush but found that it decreased liking for presidential candidate John Kerry. Study 4 also showed that MS influences actual voting intentions. In all three studies, MS increased evaluations of Bush from below the scale midpoint to above it. In addition, Study 4 revealed that whereas Kerry was preferred over Bush in the control condition, mortality salient participants preferred Bush over Kerry.

The present findings support the views of many theorists (e.g., Becker; Freud, 1921/1965; Fromm, 1941; Lifton, 1968; Lipman-Bluemen, 1996; Weber) and researchers (Bord, 1975; Ehrhart \& Klein, 2001; Kirkpatrick \& Locke, 1996; Pillai, 1996) who have noted that political allegiances are not always based on the balanced, rational forces of self-interest suggested by the Jeffersonian notion of democracy but also on the operation of nonrational forces of which we are not always aware. From the perspective of TMT, it is the need to manage concerns about personal mortality that lead people to cling to the protection provided by their leaders. By showing that reminders of both death and the 9/11 terrorist attacks increase support for President Bush and that even very subtle reminders of $9 / 11$ increase the accessibility of death-related thoughts, the present research provides clear support for this TMT analysis.

The political orientation measure in Studies 3 and 4 suggests that the increased appeal of President Bush in response to reminders of death or the events of $9 / 11$ was not at all limited to conservative individuals and was not the result of an increase in political conservatism. These null findings regarding political orientation must, of course, be interpreted with caution and could reflect insensitivity of the one-item, albeit face valid, measure. 
However, it is consistent with earlier findings. Greenberg et al. (1992) and McGregor et al. (1998) manipulated MS in conservative and liberal participants and in neither case did the dependent measures suggest a shift in political orientation of the liberals toward conservatism. In addition, in Cohen et al. (in press), the descriptions of the hypothetical candidates did not imply anything about their political orientation, making it unlikely that the MS-induced increase in preference for the charismatic candidate reflected a conservative shift. These points notwithstanding, further research on the effects of MS and 9/11 reminders on political orientation as well as the appeal of leaders is certainly warranted.

The present findings raise a variety of intriguing questions for future research. The fact that MS decreased the appeal of Kerry in Study 4 suggests that there is something specific about President George W. Bush that makes him especially useful for terror management purposes. Still, President Bush is a multidimensional stimulus so it is difficult to be definitive about precisely what makes him more appealing to Americans after a reminder of death. However, related research points to a few likely factors. One is his status as the president of the country. This position makes him the person most representative of the United States at the current time. If MS increases pro-U.S. sentiment in Americans, as a considerable body of evidence indicates, positive responses toward the president also are likely to be increased. Consistent with this idea that the sitting president will be more appealing when concerns about death are afoot, there have been numerous instances of increased presidential popularity at times when the nation is facing a serious threat. According to Gallup (http:/ /www.gallup. $\mathrm{com} /$ ), Franklin D. Roosevelt saw his approval ratings surge 12 points following the Pearl Harbor bombings, John F. Kennedy's approval rose 13 points following the Cuban missile crisis, and George H. W. Bush (the first Bush administration) saw a dramatic 18-point surge following the start of the Gulf war.

Second, President Bush has certain elements of a charismatic style: He appears highly self-confident and certain of his views (Feldmann, 2004), appeals to patriotism, and emphasizes the positive qualities of America and being American and the central role of the United States in triumphing over evil and defending freedom. Cohen et al. (in press) found that MS increases preference for a hypothetical candidate who embodies precisely this style, and one could argue that the earlier leaders FDR, JFK, and even Bush senior exemplified certain elements of this style. A third possible factor is Bush's advocacy of strong security and aggressive military measures. Although it would be useful to determine the relative contributions of these different facets of Bush, this would be a difficult task because Bush and his positions are unique. Although in Study 4 we compared Bush to John Kerry, Kerry's qualities are less clear, and he seems to lack all three of those elements. In contrast, a past leader such as Reagan had all three qualities but differs in no longer being influential. Indeed, we would suggest that these three attributes tend to covary in political leaders and act in concert to contribute to who President Bush is as a public figure.

Although the present findings are consistent with a TMT analysis, could they also be interpreted as stemming from the more general phenomenon of increased ingroup cohesion and favoritism in the face of a shared external threat? More specifically, research both in (Gaertner \& Dovidio, 2000) and outside the laboratory (Piliavin, Rodin, \& Piliavin, 1969; Sherif, 1966; Sherif, Harvey, White, Hood, \& Sherif, 1961) has shown that facing or even anticipating (Darley \& Morris, 1975) a common enemy or threat can activate superordinate identities and increase ingroup solidarity. Based on this research, perhaps reminders of $9 / 11$ and the threat of terrorism united people in a common cause and a singularly integrated identity, leading them to "rally "round the flag" and support their current leader. Although this analysis resembles our terror management analysis in some respects, there are a number of reasons why we believe that a common enemy explanation cannot adequately account for the current findings. First, applying this alternative to the MS effects observed in Studies 1, 3, and 4 requires positing that MS spontaneously activated cognitions associated with $9 / 11$ and terrorism. Although possible, this is unlikely because, according to two raters unaware of the purpose, none of the completions of the open-ended items about death in any of the three studies mentioned $9 / 11$, terrorism, war, or violence-related words or themes. Second, all participants in Studies 1 and 3 were exposed to a paragraph that made explicit mention of $9 / 11$ and future terrorist threats, so the common enemy theme was prominent in all conditions of both studies, yet MS participants showed the highest support for Bush. Third, in Study 4, we found the same effect of MS with no mention of $9 / 11$ or terrorism at all. Finally, in the typical common enemy scenario, the similarity of circumstance heightens group cohesion even among ingroup members who previously held conflicting beliefs. However, multiple studies have demonstrated that MS has the opposite effect, increasing disdain for or distancing from those with differing values and beliefs (e.g., Arndt, Greenberg, Schimel, Pyszczynski, \& Solomon, 2002; Florian \& Mikulincer, 1997; Greenberg et al., 1990; Rosenblatt et al., 1989). Although it is possible that MS and 9/11 salience activated two distinct processes, heightened accessibility of death-related thought provides the most parsimonious account of the full set of findings. Although the present results are unlikely to 
reflect a simple act of "rallying 'round the flag," one could view the salience of a common enemy or threat as one circumstance likely to increase the accessibility of death-related thought; in this light, TMT may help explain why external threats intensify ingroup favoritism and unanimity.

\section{Political Implications}

No matter how bad Bush does on the war and $9 / 11$, just having voters think about it kills us.

-Democratic strategist, quoted in Time, May 3, 2004, p. 32

The present results clearly show that President Bush's popularity is increased when thoughts of death or terrorism are especially salient, and this is particularly relevant to ongoing campaign strategies as the 2004 presidential election approaches and for future political campaign strategies as well. Indeed, the results of Study 4 clearly show that mortality-salient participants were more inclined to reelect President Bush as opposed to presidential candidate Kerry. The fact that reminders of death and the events of 9/11 enhanced support for President Bush in the present studies may not bode well for the philosophical democratic ideal that political preferences are the result of rational choice based on an informed understanding of the relevant issues. If the effect of MS on attraction to leaders is indeed rooted in the largely irrational symbolic protection that they provide, the best antidote to this problem may be to take great pains to encourage people to vote with their "heads" rather than their "hearts," because past research (Simon et al., 1997) has demonstrated that MS effects are attenuated by instructions to think rationally. Of course, in these frightening times, when the media is rife with images of death and the threat of terrorist acts is increasingly imminent, rationally driven decisions may be unlikely. But perhaps the knowledge of how concerns about death influence human behavior can promote campaign strategies and electoral choices based on the political issues and qualifications of the candidates rather than based on rhetoric primarily serving defensive needs to preserve psychological equanimity in the face of death.

\section{NOTES}

1. Only in mid-May 2004, in light of the global scandal regarding American treatment of Iraqi detainees, escalating gas prices, and no end of the fighting in Iraq in sight, has Bush's approval finally dipped below pre-9/11 levels.

2. Due to an error, only 32 of the 60 items from the PANAS-X were included in this questionnaire. Consequently, affect subscales were constructed from these items. This was rectified for Studies 3 and 4 with the same results as obtained in this study.

3 . We thank an anonymous reviewer for pointing this out.

\section{REFERENCES}

Aiken, L. S., \& West, S. G. (1991). Multiple regressions: Testing and interpreting interactions. Newbury Park, CA: Sage.

Alterman, E., \& Green, M. (2004). The book on Bush: How George W. (mis)leads America. New York: Viking.

Anonymous. (2004). Imperial hubris: Why the West is losing the war on terrorism. New York: Brasseys, Inc.

Arndt, J., Cook, A., \& Routledge, C. (in press). The blueprint of terror management: Understanding the cognitive architecture of psychological defense against death-related thought. In J. Greenberg, S. Koole, \& T. Pyszczynski (Eds.), Handbook of empirical existential psychology. New York: Guilford.

Arndt, J., Greenberg, J., \& Cook, A. (2002). Mortality salience and the spreading activation of worldview-relevant constructs: Exploring the cognitive architecture of terror management. Journal of Experimental Psychology: General, 131, 307-324.

Arndt, J., Greenberg, J., Pyszczynski, T., \& Solomon, S. (1997a). Subliminal exposure to death-related stimuli increases defense of the cultural worldview. Psychological Science, 8, 379-385.

Arndt, J., Greenberg, J., Schimel, J., Pyszczynski, T., \& Solomon, S. (2002). To belong or not belong, that is the question: Terror management and identification with ethnicity and gender. Journal of Personality and Social Psychology, 83, 26-43.

Arndt, J., Greenberg, J., Solomon, S., Pyszczynski, T., \& Simon, L. (1997b). Suppression, accessibility of death-related thoughts, and cultural worldview defense: Exploring the psychodynamics of terror management. Journal of Personality and Social Psychology, 73, 518.

Becker, E. (1971). The birth and death of meaning (2nd ed.). New York: Free Press.

Becker, E. (1973). The denial of death. New York: Free Press.

Becker, E. (1975). Escape from evil. New York: Free Press.

Berke, R. L., \& Sanger, D. E. (2001, September 9). Bush's aides seek to focus efforts on the economy. The New York Times, Section 1, p. 1.

Bord, R. J. (1975). Toward a social-psychological theory of charismatic social influence processes. Social Forces, 53, 485-497.

Carney, J., \& Dickerson, J. F. (2001, October 22). A work in progress: Bush is growing - and graying - before our eyes. An inside report on the making of a leader. Time Magazine.

Clarke, R. (2004). Against all enemies: Inside America's war on terror. New York: Free Press.

Cohen, F., Solomon, S., Maxfield, M., Pyszczynski, T., \& Greenberg, J. (in press). Fatal attraction: The effects of mortality salience on evaluations of charismatic, task-oriented, and relationship-oriented leaders. Psychological Science.

Darley, J., \& Morris, W. N. (1975). Effects of stress and commonality of fate on helping behavior. Journal of Personality and Social Psychology, $31,145-149$.

Dean, J. (2004). Worse than Watergate: The secret presidency of George W. Bush. Boston: Little, Brown.

Dworkin, R. (2002). The threat to patriotism. In G. Calhoun, P. Prince, \& A. Timmer (Eds.), Understanding September 11 (pp. 273284). New York: New Press.

Ehrhart, M. G., \& Klein, K. J. (2001). Predicting follower's preferences for charismatic leadership: The influence of follower values and personality. Leadership Quarterly, 12, 153-179.

Etzioni, A. (2002, August 28). How democracy is preserved. Christian Science Monitor, pp. 1-2.

Feldmann, L. (2004, April 16). Presidents as communicators in wartime. Retrieved from http://www.csmonitor.com/2004/0416/ p03s01-uspo.htm.

Florian, V., \& Mikulincer, M. (1997). Fear of death and the judgment of social transgressions: A multidimensional of terror management theory. Journal of Personality and Social Psychology, 73, 369-380.

Frank, J. (2004). Bush on the couch: Inside the mind of the President. New York: Regan Books.

Freud, S. (1965). Group psychology and the analysis of the ego. New York: Bantam Books. (Original work published 1921)

Fromm, E. (1941). Escape from freedom. New York: Avon Books. 
Gaertner, S. L., \& Dovidio, J. F. (2000). Reducing intergroup bias: The common ingroup identity model. Philadelphia: U.S. Psychology Press/Taylor \& Francis.

Gilbert, D. T., \& Hixon, J. G. (1991). The trouble of thinking: Activation and application of stereotypic beliefs. Journal of Personality and Social Psychology, 50, 269-280.

Goldenberg, J. L., Cox, C. R., Pyszczynski, T., Greenberg, J., \& Solomon, S. (2002). Understanding human ambivalence about sex: The effects of stripping sex of meaning. Journal of Sex Research, 39 , 310-320.

Greenberg, Greenberg, J., Simon, L., Solomon, S., Pyszczynski, T., \& Lyon, D. (1995). Assessing alternative explanations of mortality salience effects: Terror management, value accessibility, or aversive thoughts? European Journal of Social Psychology, 25, 417-433.

Greenberg, J., Martens, A., Jonas, E., Eisenstadt, D., Pyszczynski, T., \& Solomon, S. (2003). Detoxifying thoughts of death: Eliminating the potential for anxiety eliminates the effects of mortality salience on worldview defense. Psychological Science, 14, 516-519.

Greenberg, J., Pyszczynski, T., \& Solomon, S. (1986). The causes and consequences of a need for self-esteem: A terror management theory. In R. F. Baumeister (Ed.), Public self and private self (pp. 189212). New York: Springer-Verlag.

Greenberg, J., Pyszczynski, T., Solomon, S., Rosenblatt, A., Veeder, M., Kirkland, S., et al. (1990). Evidence for terror management, II: The effects of mortality salience on reactions to those who threaten or bolster the cultural worldview. Journal of Personality and Social Psychology, 58, 308-318.

Greenberg, J., Pyszczynski, T., Solomon, S., Simon, L., \& Breus, M. (1994). Role of consciousness and accessibility of death-related thoughts in mortality salience effects. Journal of Personality and Social Psychology, 67, 627-637.

Greenberg, J., Simon, L., Harmon-Jones, E., Solomon, S., Pyszczynski, T., \& Chatel, D. (1995). Testing alternative explanations for mortality effects: Terror management, value accessibility, or worrisome thoughts? European Journal of Social Psychology, 12, 417-433.

Greenberg, J., Simon, L., Porteus, J., Pyszczynski, T., \& Solomon, S. (1995). Evidence of a terror management function of cultural icons: The effects of mortality salience on the inappropriate use of cherished cultural symbols. Personality and Social Psychology Bulletin, 21, 1221-1228.]

Greenberg, J., Simon, L., Pyszczynski, T., Solomon, S, \& Chatel, D. (1992). Terror management and tolerance: Does mortality salience always intensify negative reactions to others who threaten ones worldview?. Journal of Personality and Social Psychology, 63, 212220 .

Greenberg, J., Solomon, S., \& Pyszczynski, T. (1997). Terror management theory of self-esteem and social behavior: Empirical assessments and conceptual refinements. In M. P. Zanna (Ed.), Advances in experimental social psychology (Vol. 29, pp. 61-139). New York: Academic Press.

Huddy, L., Khatid, N., \& Capelos, T. (2002). Trends: Reactions to the terrorism attacks of September 11, 2001. Public Opinion Quarterly, $66,418-450$.

Humberman, J. (2004). The Bush-hater's handbook. New York: Thunder's Mouth Press.

Kirkpatrick, S. A., \& Locke, E. A. (1996). Direct and indirect effects of three core charismatic leadership components on performance and attitudes. Journal of Applied Psychology, 81, 36-51.

Landau, M. J., Johns, M., Greenberg, J., Pyszczynski, T., Martens, A., Goldenberg, J. L., et al. (in press). A function of form: Terror management and structuring the social world. Journal of Personality and Social Psychology.

Langer, G. (2001, May 7). Prayers for victims, support for reprisals. Retrieved from http://abcnews.go.com/sections/us/DailyNews/ wtc_abcpoll010911.html.

Lifton, R. J. (1968). Revolutionary immortality: Mao Tse-tung and the Chinese cultural revolution. New York: Random House.

Lipman-Bluemen, J. (1996). The connective edge: Leading in an interdependent world. San Francisco: Jossey-Bass.
McGregor, H., Lieberman, J. D., Solomon, S., Greenberg, J., Arndt, J., Simon, L., et al. (1998). Terror management and aggression: Evidence that mortality salience motivates aggression against worldview threatening others. Journal of Personality and Social Psychology, 74, 590-605.

Mikulincer, M., Florian, V., \& Hirschberger, G. (2003). The existential function of close relationships: Introducing death into the science of love. Personality and Social Psychology Review, 7, 20-40.

Miller, C. H., \& Landau, M. J. (in press). Communication and the causes and costs of terrorism: A terror management perspective. In D. O'Hair, R. Health, \& G. Ledlow (Eds.), Terrorism: Communication and rhetorical perspectives. Cresskill, NJ: Hampton Press.

Moore, D. W. (2001, May 7) . Americans see terrorist attacks as "acts of war." Retrieved from http://www.gallup.com/content/login.aspx?ci= 4879

Morin, R., \& Dean, C. (2001, October 8). Public support is overwhelming; poll finds 94\% favor Bush's ordering strikes on Afghanistan. The Washington Post, p. A5.

Phillips, K. (2004). American dynasty: Aristocracy, fortune, and the politics of deceit in the house of Bush. New York: Viking.

Piliavin, I. M., Rodin, J. A., \& Piliavin, J. (1969). Good Samaritanism: An underground phenomenon? Journal of Personality and Social Psychology, 13, 289-299.

Pillai, R. (1996). Crisis and the emergence of charismatic leadership in groups: An experimental investigation. Journal of Applied Psychology, 26, 543-562.

PollingReport.com. (2004, May 7). President Bush: Job ratings. Retrieved from http://www.pollingreport.com/BushJob.htm.

Purdum, T. S. (2001, September 17). After the attacks: The White House; Bush warns of a wrathful, shadowy and inventive war. The New York Times, p. A2.

Pyszczynski, T., Greenberg, J., \& Solomon, S. (1999) . A dual-process model of defense against conscious and unconscious deathrelated thoughts: An extension of terror management theory. Psychological Review, 106, 835-845.

Pyszczynski, T., Solomon, S., \& Greenberg, J. (2003). In the wake of 9/11: The psychology of terror. Washington, DC: American Psychological Association.

Redl, F. (1942). Group emotion and leadership. Psychiatry, pp. 573-596.

Risen, J. (2004, April 28). How pair's finding on terror led to clash on shaping intelligence. The New York Times, p. 1.

Rosenblatt, A., Greenberg, J., Solomon, S., Pyszczynski, T., \& Lyon, D. (1989). Evidence for terror management theory I: The effects of mortality salience on reactions to those who violate or uphold cultural values. Journal of Personality and Social Psychology, 57, 681-690.

Rosenthal, R., Rosnow, R. L., \& Rubin, D. B. (2000). Contrasts and effect sizes in behavioral research: A correlational approach. Cambridge, UK: Cambridge University Press.

Rutenberg, L., \& Sander, D. E. (2004, March 12). Bush campaign goes on attack in new anti-Kerry ads. The New York Times, p. A18.

Sherif, M. (1966). In common predicament: Social psychology of intergroup conflict and cooperation. Boston: Houghton-Mifflin.

Sherif, M., Harvey, O. J., White, B. J., Hood, W. R., \& Sherif, C. W. (1961). Intergroup cooperation and competition: The Robbers Cave experiment. Norman, OK: University Book Exchange.

Simon, L., Greenberg, J., Harmon-Jones, E., Solomon, S., Pyszczynski, T., Arndt, J., et al. (1997). Cognitive-experiential self-theory and terror management theory: Evidence that terror management occurs in the experiential system. Journal of Personality and Social Psychology, 72, 1132-1146.

Solomon, S., Greenberg, J., \& Pyszczynski, T. (1991). A terror management theory of social behavior: The psychological functions of self-esteem and cultural worldviews. In M. P. Zanna (Ed.), Advances in experimental social psychology (Vol. 24, pp. 93-159). New York: Academic Press.

Solomon, S., Greenberg, J., \& Pyszczynski, T. (in press). The cultural animal: Twenty years of terror management theory and research. In J. Greenberg, S. L. Koole, \& T. Pyszczynski (Eds.), Handbook of experimental existential psychology. New York: Guilford. 
Suskind, R. (2004). The price of loyalty: George W. Bush, the White House, and the education of Paul O'Neill. New York: Simon \& Schuster.

Toner, R., \& Elder, J. (2001, December 12). Public is wary but supportive on rights curbs. The New York Times, p. 1.

Unger, C. (2004). House of Bush, house of Saud. New York: Scribner.

Waldman, P. (2004). Fraud: The strategy behind the Bush lies and why the media didn't tell. Naperville, IL: Sourcebooks Trade.
Watson, D., \& Clark, L. A. (1991). The PANAS-X: Preliminary manual for the positive and negative affect schedule-expanded form. Unpublished manuscript, Southern Methodist University, Dallas, Texas.

Woodward, B. (2004). Plan of attack. New York: Simon \& Schuster.

Received April 29, 2004

Revision accepted May 21, 2004 